PUBLISHER'S ERRATUM

Jun Mu • Tohru Uehara - Takeshi Furuno

\title{
Regulation effect of Phyllostachys pubescen methanol extractives on growth of seed plants
}

Published online : March 28, 2006

Due to a processing error, first author's name is missing in the HTML version of this article abstract page. The correct authors are given this page.

The online version of the original article can be found at http://dx.doi.org/10.1007/s 10086-005-0768-x

J. Mu. T. Uehara( $(\bowtie)$. T. Furuno

Faculty of Science and Engineering, Shimane University, Matsue

690-8504, Japan

Tel. +81-852-32-6565: Fax +81-852-32-6123

e-mail: uehara@riko.shimane-u.ac.jp

J. $\mathrm{Mu}$

College of Material Science and Technology, Beijing Forestry

University, Beijing 100083, China 